\title{
Chemical Vapor Deposition of Si/SiC Nano-Multilayer Thin Films
}

\author{
A. Weber, ${ }^{1}$ R. Remfort, ${ }^{2}$ N. Woehrl ${ }^{1, a)}$, W. Assenmacher,${ }^{3}$ S. Schulz ${ }^{1}$ \\ ${ }^{1}$ Faculty of Chemistry and CENIDE, University Duisburg-Essen, 45141 Essen, Germany \\ ${ }^{2}$ Faculty of Physics and CENIDE, University Duisburg-Essen, 47057 Duisburg, Germany \\ ${ }^{3}$ Institute of Inorganic Chemistry, University of Bonn, Römerstr. 164, D-53117 Bonn, \\ Germany.
}

Stoichiometric $\mathrm{SiC}$ films were deposited with the commercially available single source precursor $\mathrm{Et}_{3} \mathrm{SiH}$ by classical thermal chemical vapour deposition (CVD) as well as plasma-enhanced CVD at low temperatures in the absence of any other reactive gases. Temperature-variable deposition studies revealed that polycrystalline films containing different $\mathrm{SiC}$ polytypes with a $\mathrm{Si}$ to carbon ratio of close to $1: 1$ are formed at $1000^{\circ} \mathrm{C}$ in thermal CVD process and below $100^{\circ} \mathrm{C}$ in the plasma-enhanced CVD process. The plasma enhanced CVD process enables the reduction of residual stress in the deposited films and offers the deposition on temperature sensitive substrates in the future. In both deposition processes the film thickness can be controlled by variation of the process parameters such as the substrate temperature and the deposition time. The resulting material films were characterized with respect to their chemical composition and their crystallinity using scanning electron microscope, energy dispersive X-ray spectroscopy (XRD), atomic force microscopy, X-Ray Diffraction, grazing incidence X-ray diffraction, secondary ion mass spectrometry and Raman spectroscopy. Finally, Si/SiC multilayers of up to 10 individual layers of equal thickness (about $450 \mathrm{~nm}$ ) were deposited at $1000^{\circ} \mathrm{C}$ using $\mathrm{Et}_{3} \mathrm{SiH}$ and $\mathrm{SiH}_{4}$. The resulting multilayers features amorphous $\mathrm{SiC}$ films alternating with Si films,

\footnotetext{
${ }^{\text {a} C}$ Corresponding author. E-mail: nicolas.woehrl@uni-due.de, Tel: +49 203379 8126, Fax: +49 203 379 4242, Carl-Benz-Str. 199, 47057 Duisburg
} 
which feature larger crystals up to $300 \mathrm{~nm}$ size as measured by transmission electron microscopy as well as by XRD. XRD features three distinct peaks for $\mathrm{Si}(111), \operatorname{Si}(220)$ and $\mathrm{Si}(311)$.

Keywords: Silicon, Silicon Carbide, Multilayer, Plasma-CVD, Thermal CVD,

\section{INTRODUCTION}

Amorphous and crystalline $\mathrm{Si} / \mathrm{SiC}$ multilayer films have been investigated due to their potential applications in thermal and mechanical coating technology [1, 2], optoelectronics [3], telecommunication technology [4] and in cost-effective thin-film thermoelectric power generation devices [5, 6, 7]. The low thermal conductivity of these multilayers qualifies them as thermal barrier on devices operating at high temperatures [5]. Owing to the high wear resistance and the ability to oppress crack propagation, $\mathrm{Si} / \mathrm{SiC}$ multilayers are used as protective layer on optical and electronic devices [5]. Furthermore, amorphous, hydrogenated $\mathrm{Si} / \mathrm{SiC}$ multilayers are employed as photodiodes or photodetectors since they show excellent sensitivity and selectivity in the ultraviolet and visible spectrum $[8,9,10]$. Moreover, $\mathrm{Si} / \mathrm{SiC}$ multilayers were used in thermoelectric power generators as an alternative to $\mathrm{Si} / \mathrm{SiGe}$ quantum wells, which were used as n-type leg in general. $\mathrm{Si} / \mathrm{SiC}$ quantum wells consisting of alternating $\mathrm{Si}$ and $\mathrm{SiC}$ thin films with a thickness of $100 \mathrm{~nm}$ show better conversion efficiency with increasing temperature [6], which results from the increasing Seebeck coefficient and the decreasing electrical resistance at elevated temperature [7]. Compared with Germanium, which is a rather rare material, silicon and carbon are abundant elements and thus a cost efficient alternative to classical thermoelectric materials.

$\mathrm{Si} / \mathrm{SiC}$ multilayer films are usually deposited using dual source precursors. Silane or disilane are typically employed as silicon sources whereas hydrocarbons such as methane, propane or acetylene are used as carbon sources. De Cesare et al. used plasma enhanced chemical vapour deposition (PECVD) to synthesize amorphous and hydrated $\mathrm{Si} / \mathrm{SiC}$ multilayers at temperatures between 140 and $300{ }^{\circ} \mathrm{C}$ with silane and methane as precursors [8,9,11]. Silane and propane are used in a RTCVD rapid thermal chemical vapor deposition (RTCVD) process to deposit $\beta$-SiC heteroepitaxially on Si substrates at 
temperatures of $1200{ }^{\circ} \mathrm{C}$ with $\mathrm{H}_{2}$ as reactive gas [12]. Myong et al. also utilized $\mathrm{H}_{2}$ as reactive gas to deposit $\mathrm{Si} / \mathrm{SiC}$ multilayers with silane and acetylene in a photo-CVD process [13, 14]. Si/SiC multilayers with $\mathrm{SiC}$ and $\mathrm{Si}$ film thicknesses of 8 and $14 \mathrm{~nm}$, respectively, were deposited by physical vapour deposition (sputtering) and the temperature dependent thermal conductivity of $\mathrm{Si} / \mathrm{SiC}$ multilayers was determined [5].

In this paper, we present the deposition of $\mathrm{SiC}$ films with the commercial available single source precursor $\mathrm{Et}_{3} \mathrm{SiH}$. Two CVD processes (PECVD and thermal CVD) are used to deposit $\mathrm{SiC}$ films in order to compare the resulting film properties. The PECVD method allows the deposition of films at low temperatures. No other reactive gases are required to achieve the growth of stoichiometric, amorphous or crystalline $\mathrm{SiC}$ films. The influence of the substrate temperature on the growth process is demonstrated by measuring the growth rate and characterization of the film properties by XRD.

Thereby the film thickness was decreased without changing the film quality and the roughnesses of the deposited films was measured to be very low. Finally, the deposition of $\mathrm{Si} / \mathrm{SiC}$ multilayers with a single source precursor are presented. Sequential deposition of $\mathrm{Si}$ and $\mathrm{SiC}$ films using $\mathrm{SiH}_{4}$ and $\mathrm{Et}_{3} \mathrm{SiH}$ at 1000 ${ }^{\circ} \mathrm{C}$ by thermal CVD process allowed the fabrication of a four-layer and a ten-layer structure which has high potential value for mechanical applications as well as for thermoelectric applications.

\section{EXPERIMENTAL DETAILS}

\subsection{Thermal CVD}

Thermal deposition experiments were performed in a custom-made cold-wall metalorganic chemical vapour deposition (MOCVD) reactor equipped with an inductively heated graphite susceptor, which allows a maximum temperature of the silicon substrate of up to $1200{ }^{\circ} \mathrm{C}$. Three different organosilanes $\left(\mathrm{Et}_{3} \mathrm{SiH}, \mathrm{Me}_{4} \mathrm{Si}, \mathrm{PhSiH}_{3}\right)$ were investigated as single source precursors for the deposition of $\mathrm{SiC}$ material films in the temperature range from 900 to $1200{ }^{\circ} \mathrm{C}$ in the custom-made cold-wall reactor, from which 
$\mathrm{Et}_{3} \mathrm{SiH}$ was identified as the most suitable single source precursor for the deposition of stoichiometric SiC films. Temperature-variable deposition studies revealed $1000{ }^{\circ} \mathrm{C}$ as the best substrate temperature for $\mathrm{SiC}$ film growth using $\mathrm{Et}_{3} \mathrm{SiH}$ at a flow rate of $2 \mathrm{sccm}$. Polycrystalline films of cubic-type $\mathrm{SiC}$ with Si to carbon ratio of close to 1:1 were obtained under these deposition conditions. To avoid the formation of particles on the surface the precursor gas flow was diluted with an argon carrier gas. The dilution ratio of 1:80 emerged as the most effective.

\subsection{Plasma CVD}

PECVD studies were performed in order to deposit thin SiC films on silicon substrates at lower substrate temperatures and to compare the properties of the resulting $\mathrm{SiC}$ films with those obtained from the classical thermal MOCVD process. The silicon substrates were cut out of single crystalline $<100>$ oriented Si wafers with a production tolerance of $+-0.5^{\circ}$ and the surface was ultrasonically cleaned in acetone for $30 \mathrm{~min}$ prior to the deposition process. In order to compare the two deposition techniques in detail, the same precursor that was found to give the best results in thermal CVD $\left(\mathrm{Et}_{3} \mathrm{SiH}\right)$ was used in the plasma process for the deposition of the SiC films. Since the precursor is decomposed in the plasma, the substrate temperature required for the PE-deposition of $\mathrm{SiC}$ thin films was expected to be lower compared to the thermal CVD process. A special plasma source was utilized to adjust the particle energies in the plasma giving the opportunity to investigate the influence of the plasma parameters on the resulting film properties in a wide range. The vacuum recipient is a gaseous electronics conference reference cell [15], which is equipped with a hybrid capacitive and inductive radio frequency (RF) plasma source $(13.56 \mathrm{MHz})$. The plasma source features a special antenna design that provides the possibility to vary particle flow and particle energy independent of each other. Furthermore, energies can be set to very low levels (down to plasma energy). It consists of two electrodes with RF generators, which are used for inductive, capacitive, or a combined inductive-capacitive plasma excitation. A detailed description of the plasma source can be found elsewhere [16]. 
Argon diluted $\mathrm{Et}_{3} \mathrm{SiH}$ was used as a process gas. Silicon substrates were placed on a heated substrate holder in the middle of the reactor and the substrate temperature was measured by a thermocouple. Deposition parameters such as deposition time, $\mathrm{Et}_{3} \mathrm{SiH}$ concentration and substrate temperature were systematically varied to verify their influence on the resulting film properties.

\subsection{Characterization}

The film thickness was measured by profilometry (VEECO Dektak 6M) and ellipsometry (HORIBA MM-16-FGMS). The surface morphology of the resulting films was analyzed by scanning electron microscopy (SEM; Jeol JSM 6510) using operating voltage between 5 and $15 \mathrm{kV}$. Cross section samples were prepared with the Jeol Cross-Section Polisher (Jeol IB-09010CP) and measured with a operating voltage of up to $25 \mathrm{kV}$. In addition, AFM (Veeco Dimension 3100) measurements in contact mode were performed to measure the surface roughness of the deposited films.

The chemical composition was analyzed by energy-dispersive X-ray analysis (EDX, Bruker Quantax 400 , acceleration voltage $10 \mathrm{kV}$, counting time $160 \mathrm{sec}$.). The system was calibrated using a crystalline SiC film as standard. Additionally secondary ion mass spectroscopy (SIMS) measurements were used to measure the stoichiometry of the obtained films as a function of the film thickness. SIMS of positive and negative ions were performed in a LEYBOLD LHS 10 system with a secondary ion and neutral mass spectrometer module (SSM 200) using a Balzers 511 quadrupole for mass separation. The base pressure in the analysis chamber is about $5^{*} 10^{-10}$ mbar. For sputter erosion, the samples were bombarded by a scanned focussed $5 \mathrm{keV} \mathrm{Ar}^{+}$ion beam of about $1 \mu \mathrm{A}$ under an angle of $60^{\circ}$ to the surface normal. For the presented depth profiles, the ion beam with a FWHM of about $100 \mu \mathrm{m}$ was scanned over an area of 3 $\mathrm{mm} \times 2 \mathrm{~mm}$. To increase depth resolution, sputtered particles from the crater walls are suppressed by electronic gating. 
The crystallinity of the deposited films was investigated by X-ray powder diffraction measurements $(\mathrm{XRD})$ as well as by grazing incidence X-ray diffraction (GIXRD, Panalytical Empyrean, MoK $\alpha$ radiation $=0.7107 \AA)$.

Transmission electron microscope (TEM) investigations of a four-layer Si/SiC-system deposited on a SiC substrate were conducted in a TEM FEI-Philips CM300 UT/FEG, operated at $300 \mathrm{kV}$, equipped with a Gatan CCD for image recording and with a Thermo NSS system for Energy Dispersive X-ray Spectrometry (EDS) analysis (Ge-detector). The cross section sample was prepared by the face-to-face technique and finally by dimple grinding and ion beam etching [17].

Raman Spectroscopy (Horiba-Jobin Yvon, Labram, $514 \mathrm{~nm}$ Argon laser) was used to characterize the deposited films and to identify the SiC polytype in the material.

\section{RESULTS AND DISCUSSION}

\subsection{SiC film growth by thermal CVD}

Preliminary tests revealed $\mathrm{Et}_{3} \mathrm{SiH}$ as the most suitable single source precursor for the thermal CVD deposition of stoichiometric $\mathrm{SiC}$ films at a temperature of $1000{ }^{\circ} \mathrm{C}$ in respect to the resulting composition (Si:C molar ration) and crystallinity. An "inverse" reactor geometry, in which the precursor gas was introduced from the bottom and the substrate was placed at the upper part of the reactor, was applied in order to prevent the deposition of particles on the surface from parasitic gas phase reactions (decomposition reactions) of the precursor. In addition, the precursor gas flow was diluted with argon carrier gas as the precursor concentration was found to have a strong influence on the particle formation. Four different dilution ratios with continuously increasing argon concentration $(1: 10,1: 20,1: 40$ and 1:80), which was controlled by mass flow controllers, were examined. The tendency of particle formation could clearly be reduced with increasing dilution ratio and thus decreasing $\mathrm{Et}_{3} \mathrm{SiH}_{\mathrm{H}}$ concentration indicating reduced gas-phase reaction activity. At the same time, the deposition rate is 
reduced with higher dilution ratio. Hence, the chosen dilution ratio of 1:80 in the following deposition processes is a compromise to reduce particle formation while having a sufficient deposition rate. Furthermore, the effect of deposition time on the morphology and thickness of the SiC film was investigated. We observed a decrease in particle formation on the surface with decreasing deposition time. In addition, the formation of cracks in the film, resulting from residual stress within the rather thick SiC films, was avoided under these conditions as is shown in Fig. 1.

The thickness of $\mathrm{SiC}$ films deposited at $1000{ }^{\circ} \mathrm{C}$ can be easily controlled by the deposition time as shown by detailed time-dependent deposition studies. Fig. 1 shows the cross section images of the resulting SiC films, from which the film thickness was measured. An almost linear correlation between deposition time and film thickness was found as shown in Fig 2. The average growth rate equals the slope of the best fit line and corresponds to $4.2 \mu \mathrm{m} / \mathrm{h}$. This value is considerably higher than the growth rates determined for the single source precursors trimethylsilane $(0.54 \mu \mathrm{m} / \mathrm{h})[18]$ and 1,3 -Disilabutane $(0.02 \mu \mathrm{m} / \mathrm{h})$ [19], which were used for heteroepitaxial growth of crystalline $\beta$-SiC (cubic-type) films. As the growth rate is not only influenced by the deposition time but also by the reactor pressure and the composition of the gas phase, the comparison of these values is rather difficult. Moreover, not only the deposition conditions differ but also the composition of the gas phase because different precursors and a reactive gas $\left(\mathrm{H}_{2}\right)$ were used.

Due to the almost linear correlation of deposition time and film growth rate a controlled film growth is possible at $1000{ }^{\circ} \mathrm{C}$ with $\mathrm{Et}_{3} \mathrm{SiH}$ as single source precursor. Even though the standard relative error of the thickness measurements can be estimated to be $\sim 10 \%$ (due to roughness, film inhomogeneity), it can be extrapolated that films of $10-20 \mathrm{~nm}$ will be deposited within $10-20$ seconds using highly diluted $\mathrm{Et}_{3} \mathrm{SiH}$ in $\operatorname{Ar}(1: 80)$ as calculated from the slope $(\mathrm{m}=64.22 \mathrm{~nm} / \mathrm{min})$ of the best-fit line in Fig 2.

One important film property to control is the residual stress in the deposited films. High residual stress in thin films leads to reduced adhesion and thus delamination of the film from the substrate. In other 
cases the residual stress leads to cracks in the films limiting their functional capability. Residual stress in thin films need to be taken into account in particular when depositing thin multilayers because intrinsic stresses and the thermal stresses due to differences in the thermal expansion coefficients of the materials add up from every individual layer. On the other hand, the control of the residual stress can be used to compensate the stresses in the individual films, leading to no notable stress in the multilayer.

In Fig. $1 \mathrm{~d}$ a crack is visible in the $\mathrm{SiC}$ film, which arises from tensile stresses in the synthesized film. The deposition of the $\mathrm{SiC}$ films on $\mathrm{Si}$ substrates at high temperatures and the subsequent cooling to room temperature leads to high strain due to the lattice mismatch $(20 \%$ for $3 \mathrm{C}-\mathrm{SiC}$ and $\mathrm{Si}(100))$ and the difference in thermal expansion coefficients $\left(\alpha_{\mathrm{SiC}}=3.5 \times 10^{6} \mathrm{~K}^{-1}\right.$ and $\alpha_{\mathrm{Si}}=2.616 \times 10^{6} \mathrm{~K}^{-1}$ at room temperature $[20,21])$. Considering the aspect of residual stress the deposition at the lowest possible temperature would be preferable.

Stress was measured by an optical method using a laser beam that is deflected in a specific angle depending on the curvature of the samples. With this curvature and the Stoney equation it is possible to calculate the residual stress in the film [22]. Depending on the deposition parameters the stresses in the films were measured to be between 0 and $2 \mathrm{GPa}$. Since the residual stress scales with the film thickness, cracks in the SiC films were observed especially in the thicker films deposited in this work. In the thinner films no visible failure and fracture was found.

Raman measurements of SiC films on silicon substrates are shown in Fig. 3. SiC is known to have more than 170 different polytypes [23]. The most common polytypes are the cubic (3C-SiC) and the $4 \mathrm{H}$ and $6 \mathrm{H}$ hexagonal $(\alpha-\mathrm{SiC})$ types. The existence of polymorphs arises from different stacking of the close packed layers which results in different periodicities and thus in different unit cells and crystal systems. SiC films deposited by CVD methods frequently consist of a mixture of hexagonal and cubic stackings. Due to this mixture of polytypes these films often contain a random distribution of stacking faults of the close-packed atomic plains. Raman spectroscopy is a suitable analytical tool to identify the polytype 
structures of the $\mathrm{SiC}$ fractions in the thin films. Furthermore, analysis of the peak position and the FWHM can help to measure residual stress in the crystals and the crystal size since the Raman bands in SiC crystals containing stacking disorders exhibit broadening and distortion. The control of the polymorph during crystal growth can be an essential, because the band gap energy and electrical properties change with the type of polymorph.

Fig. 3 displays Raman spectra of three samples of SiC films on silicon substrates, which were measured by back scattering geometry. The SiC film shown in Fig. 3a is very thin $(200 \mathrm{~nm})$ and thus the spectrum is dominated by features arising from the Si substrate, namely the intense line of the lattice vibration at $520 \mathrm{~cm}^{-1}$ and the broad feature between $950-990 \mathrm{~cm}^{-1}$ (second-order of Si). The films measured in Fig. $3 \mathrm{~b}$ and $3 \mathrm{c}$ are much thicker ( 2 and $9 \mu \mathrm{m}$, respectively) and the folded modes of transverse acoustic (FTA) and optic (FTO) branches are the dominating features of the spectra. As the unit cell volume of the polytype is increased, the number of observable folded modes increases. The Raman spectra of the deposited SiC films show broad absorption bands at the frequencies corresponding to those of basic polytypes [24] such as $3 \mathrm{C}, 2 \mathrm{H}, 4 \mathrm{H}, 6 \mathrm{H}$ and $8 \mathrm{H}$.

In more detail the bands at $900 \mathrm{~cm}^{-1}$ and $800 \mathrm{~cm}^{-1}$ can be assigned to the folded longitudinal optical (FLO) and the folded transverse optical (FTO) mode of the 3C polytype. The band around $500 \mathrm{~cm}^{-1}$ and $400 \mathrm{~cm}^{-1}$ can be assigned to the folded longitudinal acoustic (FLA) modes of the $6 \mathrm{H}$ and the $8 \mathrm{H}$ polytype, respectively. Finally the mode at $250 \mathrm{~cm}^{-1}$ originates from the folded transverse acoustic (FTA) branch of either $2 \mathrm{H}, 4 \mathrm{H}, 6 \mathrm{H}$ or $8 \mathrm{H}$ polytype. Each Raman spectrum shows very broad acoustical and optical modes of $\mathrm{SiC}$, indicating a low degree of crystallinity in the films, which most likely consist of small nanocrystals [25].

All SiC films show a further broad scattering feature in the Raman spectra between 1300 and $1650 \mathrm{~cm}^{-1}$ that can be attributed to amorphous carbon [26] as admixture in the SiC layer. If one compares the 
measured Raman spectra it is obvious that the intensity of the amorphous carbon feature is highest for the sample shown in Fig. 3c. This is due to the higher deposition temperatures during the synthesis $\left(1100{ }^{\circ} \mathrm{C}\right)$ giving a higher graphitization of the amorphous carbon and thus a more intense signal in the Raman spectrum.

In summary, the Raman measurements showed that the deposited $\mathrm{SiC}$ films consist of a mixture of different nanocrystalline polytypes. Additionally a fraction of amorphous carbon can be found in all the films. The low crystallinity was affirmed by XRD measurements (not shown here) and the TEM measurements shown later.

\subsection{Si film growth by thermal CVD}

Monosilane $\left(\mathrm{SiH}_{4}\right)$, which is technically used to produce high-quality silicon films, was chosen as precursor for the deposition of Si films. Although silane decomposes at considerably lower temperatures than $1000{ }^{\circ} \mathrm{C}$, this temperature was chosen for the deposition of Si films with regard to the growth of $\mathrm{Si} / \mathrm{SiC}$ multilayer films. In order to realize a dual source process, the substrate temperature should be kept constant to avoid unnecessarily temperature fluctuations. Due to different thermal expansion coefficients of silicon and silicon carbide these fluctuations could lead to stresses, which could result in cracks or delamination of the film from the substrate.

The silicon films were deposited on commercially available 2H-SiC substrates (N Type, hexagonal, $<0001>+/-0.5$ degree orientation, $<0.5 \mathrm{~nm}$ surface roughness). Because the dilution of the precursor gas flow had proven to be practical for the deposition of SiC films, the silane gas flow was also diluted with an additional argon stream in the ratio 1:80 $\left(\mathrm{SiH}_{4} / \mathrm{Ar}\right)$. Time-dependent deposition studies were carried out to determine the dependence of the deposition time on the film thickness, which is important to control for the growth of multilayers. Just as shown for the thickness of the SiC films shorter deposition times result in thinner Si films. 
The experiments yielded flat and homogenous Si films. Fig. 4 shows the cross section images of the resulting Si films deposited within 10 minutes and 1 minute respectively. The resulting Si films became smoother and the formation of Si particles on the surface was significantly reduced with decreasing deposition time.

XRD studies revealed a relatively high crystallinity, which can be seen by the distinct narrow reflexes in the diffractogram as shown in Fig. 5 for the sample deposited at $1000^{\circ} \mathrm{C}$ for 1 minute. Three intense peaks are clearly visible at $28.4^{\circ} 2 \Theta \mathrm{Si}(111), 47.5^{\circ} 2 \Theta \mathrm{Si}(220)$ and $56.1^{\circ} 2 \Theta \mathrm{Si}(311)$ in the deposited films. Calculating the crystal size from FWHM by Debye-Scherrer formula gives a crystal size of 388 $\mathrm{nm}$ for the dominant (111) crystals. Comparable crystal sizes were measured for the sample that was deposited for 10 minutes. The measured crystal sizes are in good agreement with the TEM measurements shown later.

\subsection{Si/SiC multilayer film growth by thermal CVD}

After the ideal deposition parameters have been identified for both $\mathrm{Et}_{3} \mathrm{SiH}$ and $\mathrm{SiH}_{4}$, the deposition of $\mathrm{Si} / \mathrm{SiC}$ multilayer films was investigated. Deposition studies were performed both on $\mathrm{SiC}(\mathrm{N}$ Type, hexagonal $<0001>+/-0.5$ degree orientation, $<0.5 \mathrm{~nm}$ surface roughness) and on $\mathrm{Si}(100)$ substrates using the optimized deposition conditions as summarized before $\left(1000^{\circ} \mathrm{C}, 1 \mathrm{sccm}\right.$ flow rates; $10^{-2}$ mbar; $\left.\mathrm{Et}_{3} \mathrm{SiH} / \mathrm{Ar}=1: 80 ; \mathrm{SiH}_{4} / \mathrm{Ar}=1: 80\right)$. A four-layer system was deposited on a $\mathrm{Si}(100)$ substrate and the deposition time was 2 minutes for each of the SiC and the Si layers, which was calculated to result in $200 \mathrm{~nm}$ thick films for $\mathrm{Si}$ as well as for $\mathrm{SiC}$, but cross section images of the resulting multilayer structure showed, that the SiC films were slightly thicker than the Si films. Furthermore, the terminal Si layer is more sensitive against oxidation than a SiC layer. For this reason the following deposition of multilayers were carried out on $\mathrm{SiC}$ substrates (N Type, $<0001>+/-0.5$ degree orientation, $<0.5 \mathrm{~nm}$ surface roughness). The deposition time for the Si layer was elongated to achieve films with an equal 
thickness for each layer. Four- and ten-layer systems were grown on $\mathrm{SiC}$ substrates by sequential feeding of $\mathrm{SiH}_{4}$ (deposition times were 6 minutes for the four -layer system and 3 minutes - for the tenlayer system) and $\mathrm{Et}_{3} \mathrm{SiH}$ (deposition times were 4 and 2 minutes, respectively). The thickness of the individual layers was chosen to be relatively large since this study was rather focusing on the general applicability of the precursors for multilayer growth (proof-of-concept study) than on the deposition of a multilayer film for technical application as thermoelectric material. For thermoelectric devices, thin layers of about $10 \mathrm{~nm}$ thickness of both materials are required. However, due to the analytical limitations in the characterization of such ultrathin films we decided to deposit reasonably thick layers although thinner films would be needed for some of the targeted applications (such as thermoelectrics). Nevertheless, all results obtained in this paper give us confidence that the process can be scaled down to thinner films by adjusting the process parameters identified in this work to influence the growth rate. Figs. 6 and 7 show the cross section TEM images of the resulting four-layer system grown on $c$-axis oriented hexagonal $2 \mathrm{H}-\mathrm{SiC}$ and a high resolution TEM images of the interfaces $\mathrm{SiC}$ substrate/first $\mathrm{Si}$ layer and second SiC layer/third Si layer. The layers are of almost equal thickness of $450+/-3 \mathrm{~nm}$ and have clear and rather smooth interfaces. The small roughness is a cause of the columnar crystallites without any preferential orientation relation in the Si layers. The topology of the surface of each Si layer is reproduced to the surface of the following SiC layers, and thus to the surface of the four-layer system. This is an indicator for the evenness of the SiC layers, which are mainly amorphous, but nano-crystals of ca. $10 \mathrm{~nm}$ in size can be detected in the SiC layers by contrast or by Fourier analyses of small areas of the high resolution TEM (HRTEM) images (see Fig. 7). The Si layers consist of crystals with a size of ca. $100 \mathrm{~nm}$ perpendicular and up to $300 \mathrm{~nm}$ parallel to the growing direction of the layers, as clearly shown by diffraction contrast and lattice fringes in Figs. 6 and 7. Very rarely, an orientation relation between the first $\mathrm{Si}$ layer and the $2 \mathrm{H}-\mathrm{SiC}$ substrate was observed. Figure 6 shows a Si crystal of $10 \mathrm{~nm}$ size in the boxed area in $<112>$ orientation with the closed packed $\{111\}$ lattice planes parallel to the 
$\{002\}$ lattice planes of the $c$-axis oriented hexagonal $2 \mathrm{H}-\mathrm{SiC}$ substrate in $<210>$ orientation. Although an orientation relation between the substrate and the first Si layer parallel to the closed packed layers cannot be expected by reason of the large lattice mismatch of ca. $20 \%$ of the $\{100\}$ lattice planes of $\mathrm{SiC}$ [27] with the $\{110\}$ lattice planes of $\mathrm{Si}[28]$, the smooth interface substrate/film suggests a strong adhesion without any voids and any additional phase. The EDX-linescan of the cross-section sample (Fig. 7) shows the carbon-content within the layers. The intensity of the C-K X-Ray line is used to measure the carbon content in the films. The measurement clearly shows a higher amount of carbon in the SiC layers compared to the pure Si layers. The clear and sharp ascents and descents of the carboncontent at the interfaces indicate that there is no significant diffusion between the individual layers. The surface of the sample is covered by residues of glue from the cross section preparation. The glue indicates the completeness of the last layer, and is the reason for the strong ascent of the C-K counts towards the surface of the four-layer sample.

The cross section view of the ten-layer system is shown in Fig. 8. This system also shows clear interfaces between the different material layers. The Si layers are slightly thinner than the SiC layers and the interfaces between the individual layers are rougher than in the four-layer system.

$\mathrm{Et}_{3} \mathrm{SiH}$ and $\mathrm{SiH}_{4}$ are suitable precursors for the MOCVD growth of $\mathrm{SiC} / \mathrm{Si}$ multilayer films at $1000{ }^{\circ} \mathrm{C}$. Deposition temperature, deposition time and precursor concentrations have been optimized for the growth of pure and homogeneously flat films. A proof-of-concept study showed that thick four-layer and ten-layer films can be deposited using the optimized deposition parameters.

\subsection{SiC film growth by PECVD}

The influence of the process parameters (and thus the plasma parameters) on the resulting film properties were investigated. Argon diluted $\mathrm{Et}_{3} \mathrm{SiH}$ was used as a process gas. The concentration was 
varied by changing the gas flow of the $\mathrm{Et}_{3} \mathrm{SiH}$ giving mix ratios between $50 \mathrm{sccm} / 16 \mathrm{sccm}$ and $50 \mathrm{sccm}$ / $4 \mathrm{sccm}$. Furthermore the influence of the deposition time ( $3 \mathrm{~min}$ to $30 \mathrm{~min}$ ) and the substrate temperature $\left(\mathrm{RT}\right.$ to $\left.800^{\circ} \mathrm{C}\right)$ was investigated.

To investigate the thickness of the resulting film as a function of deposition time, SiC films were deposited at different process durations. Thickness measurements shown here were obtained by using both profilometry and ellipsometry. Profilometry was used for thicker films (>30 nm) while ellipsometry was used for thinner films $(<30 \mathrm{~nm})$ where the profilometry method reached its device resolution limit. Measurements were done at multiple positions and subsequently averaged. It was found that an excellent homogeneity of the film thickness was achieved over the whole substrate area $(20 \times 10$ $\mathrm{mm})$. At constant process parameters $\left(\mathrm{Ar} / \mathrm{Et}_{3} \mathrm{SiH}=50: 16 ; \mathrm{T}=200{ }^{\circ} \mathrm{C} ; \mathrm{P}=300 \mathrm{~W}\right)$ the relationship between the deposition time and the film thickness shown in Fig. 9 was found as measured by profilometry. Short deposition times $(3 \mathrm{~min})$ yielded thin $\mathrm{SiC}$ films with thicknesses of around $30 \mathrm{~nm}$. The growth rate that can be calculated from the data points in Fig. 9 is about $3.5 \mathrm{~nm} / \mathrm{min}$. The results shown here give confidence that thin films with just a few nm thicknesses can be deposited by reducing the process time down to 1 min or even below.

The film thickness after 15 min deposition time as a function of the $\mathrm{Et}_{3} \mathrm{SiH}$ concentration is shown in Fig. 10. Since the film thickness for low $\mathrm{Et}_{3} \mathrm{SiH}$ flow is very small, the thickness was measured by Elipsometry. Argon flow was kept constant at $50 \mathrm{sccm}$ while the $\mathrm{Et}_{3} \mathrm{SiH}$ flow was increased. A higher gas flow of the growth precursor leads to higher growth rates as expected. Beyond that it is shown that rather slow growth rates can be obtained by diluting the precursor gas with Argon, giving very precise control of the resulting film thickness.

Finally, the influence of the substrate temperature on the film thickness was investigated by Profilometry. Fig. 11 shows that with higher substrate temperatures the film thickness decreases. This 
finding is in good agreement with the results of other groups for the deposition of a-SiC:H films from liquid organosilanes [29]. The decrease of the deposition rate at higher substrate temperatures can be explained by the increasing desorption probability of loosely bound hydrogen containing groups. Furthermore the higher substrate temperature results in a longer average diffusion length of the adsorbents on the substrate surface thus incorporating on energetically preferable places giving films of higher density and homogeneity.

It was shown that by controlling the crucial process parameters (deposition time, precursor concentration and substrate temperature) it is possible to deposit $\mathrm{SiC}$ films with thicknesses as low as a few nm or even below, which is a necessary precondition for thermoelectric performance of the $\mathrm{Si} / \mathrm{SiC}$ multilayer structure. This is expected to be essential for the increase of the thermoelectric performance of the multilayer system. Furthermore it was shown that SiC films can be synthesized by plasma CVD at rather low temperatures below $100{ }^{\circ} \mathrm{C}$, allowing the co-deposition of temperature sensitive materials or the use of temperature-sensitive substrate materials.

The film properties were investigated by AFM, SEM, Raman, GIXRD and SIMS methods. AFM measurements were used to measure the surface roughness of the deposited films. Fig. 12 shows the surface of the SiC film deposited for $15 \mathrm{~min}$ on a silicon substrate. A line scan of $5 \mu \mathrm{m}$ on the film surface is shown. The measurement confirms that the surface roughness is very low with $\pm 2.5 \mathrm{~nm}$ for the whole line scan as measured by peak-to-peak depth analysis.

Low surface roughness is a fundamental surface property to achieve multilayer systems with film thicknesses below $10 \mathrm{~nm}$. The results shown here prove that the PECVD is very suitable to control the film thickness and the film roughness, hence allowing the deposition of high-quality multilayer systems. 
Since the thickness of the deposited films is very low, Raman measurements couldn't provide any structural information due to the strong signal from the silicon substrate background. Thus GIXRD was used to measure the crystallinity. Measurements with small angle cause the penetration depths of X-rays to decrease significantly and the structural information obtained to be more from the thin film. Each diffractogram was measured with a fixed grazing incidence angle of $1^{\circ}$. The penetration depth of $\mathrm{Cu} \mathrm{K}_{\alpha 1}$ $(\lambda=0.15406 \mathrm{~nm})$ can be calculated for $\mathrm{SiC}$ to be around $700 \mathrm{~nm}$ at $1^{\circ}$ grazing incidence angle [30]. Since this is still relatively large compared to the film thickness only little structural information can be obtained from the data as shown in Fig 13 . The sample prepared at low temperature (below $100^{\circ} \mathrm{C}$ ) shows the peaks between $50^{\circ}$ and $60^{\circ}$ arising from the Si substrate as well as the relatively broad peak at $35.7^{\circ}$ indicating $\mathrm{SiC}$ (111). Calculating the crystal size from FWHM by Debye-Scherrer formula gives a crystal size of around $40 \mathrm{~nm}$. At higher deposition temperatures $\left(800^{\circ} \mathrm{C}\right)$ the $\mathrm{SiC}$ peak is not detected but the graphite $(002)$ at $26^{\circ}$ is measured indicating a graphitization of the film at these elevated temperatures. This increased graphitic phase was also measured by Raman spectroscopy.

SIMS (Secondary Ion Mass Spectrometry) measurements were performed to measure the chemical composition and its depth distribution in the SiC films. A relatively thick film was deposited for this measurement $\left(\mathrm{Ar} / \mathrm{Et}_{3} \mathrm{SiH}=5: 1 ; \mathrm{T}=200{ }^{\circ} \mathrm{C} ; \mathrm{t}=120 \mathrm{~min} ; \mathrm{P}=300 \mathrm{~W}\right)$. Fig. 14 shows the depth profile for the given sample.

The measurement suggests that the process parameters lead to the deposition of SiC films with a 1:1 ratio of $\mathrm{Si}$ and $\mathrm{C}$ atoms over the whole depth profile. Additionally a low contamination of the film with oxygen (around $2 \%$ ) was measured, most likely resulting from small impurities of the precursor, which was used without further purification. 


\section{CONCLUSION}

$\mathrm{Et}_{3} \mathrm{SiH}$ is a promising single source precursor for the deposition of $\mathrm{SiC}$ thin films by using either classical thermal CVD and PECVD processes at rather low temperatures (CVD: $1000{ }^{\circ} \mathrm{C}, \mathrm{PECVD}:<100$ ${ }^{\circ} \mathrm{C}$ ) in the absence of any reactive gases. Since the growth temperature of polycrystalline $3 \mathrm{C}$-SiC deposited on Silicon is lower than that of single crystalline 3C-SiC, the shown processes are fast and scalable. By careful adjustment of the specific deposition parameters, we were able to decrease the film thickness without changing the film quality. The roughnesses of the deposited films was measured to be very low. Low substrate temperatures are critical in order to suppress the residual stress in the films and to utilize the process for temperature sensitive substrates. Sequential deposition of $\mathrm{Si}$ and $\mathrm{SiC}$ films using $\mathrm{SiH}_{4}$ and $\mathrm{Et}_{3} \mathrm{SiH}$ at $1000{ }^{\circ} \mathrm{C}$ by thermal $\mathrm{CVD}$ process allowed the fabrication of a four-layer and a ten-layer structure which has high potential value for various applications.

No multilayer samples were synthesized by PECVD yet, due to the significant lower deposition rates and the consequently much more challenging film characterization on such specimen. However, the synthesis and characterization of PECVD grown multilayers for specific applications will be in the focus of future work.

\section{ACKNOWLEDGMENTS}

Dr. Axel Eicke, Zentrum für Sonnenenergie- und Wasserstoff-Forschung, Stuttgart for SIMS-SNMS measurements. 


\section{REFERENCES}

[1] E. Bertran, G. Viera, E. Martinez, J. Esteve, Y. Maniette, J. Farjas, P. Roura, Surface analysis of nanostructured ceramic coatings containing silicon carbide nanoparticles produced by plasma modulation chemical vapour deposition, Thin Solid Films 377-378 (2000) 495-500.

[2] N. P. Padture, Maurice Gell, and Eric H. Jordan, Thermal Barrier Coatings for Gas-Turbine Engine Applications, Sci. 296 (2002) 280-284.

[3] Caputo, D.; de Cesare, G.; Nascetti, A.; Tucci, M., Detailed Study of Amorphous Silicon Ultraviolet Sensor With Chromium Silicide Window Layer, IEEE Transactions on Electron Devices 55(1) (2008) 452-456.

[4] M. Vieira, P. Louro, M. Fernandes, M.A. Vieira, A. Fantoni, M. Barata, Large area double p-i-n heterostructure for signal multiplexing and demultiplexing in the visible range, Thin Solid Films, 517(23) (2009) 6435-6439.

[5] T. Borca-Tasciuc, M. Mazumder, S.C. Teehan, E. Stinzianni, H. Efstathiadis, S. Solovyov, Temperature dependent thermal conductivity of $\mathrm{Si} / \mathrm{SiC}$ amorphous multilayer films, Appl. Phys. Lett. 96 (2010) 093103.

[6] Ghamaty, S.; Bass, J.C.; Elsner, N.B., Quantum well thermoelectric devices and applications, Twenty-Second Int. Conf. on Thermoelectr. - ICT (2003) 563-566.

[7] Jovanovic, V.; Ghamaty, S.; Bass, J.C., New thermoelectric materials and applications, 13th IEEE Intersoc. Conf. on therm. and Thermomechanical Phenom. in Electron. Syst. (ITherm) (2012) 1159-1169.

[8] G. deCesare, F Irrera, F. Lemmi, F. Palma, Amorphous Si/SiC three color detector with adjustable threshold, Appl. Phys. Lett. 66(10) (1995) 1178-1180.

[9] G. deCesare, F. Irrera, F. Palma, M. Tucci, E. Jannitti, G. Naletto, P. Nicolosi, Amorphous silicon/silicon carbide photodiodes with excellent sensitivity and selectivity in the vacuum ultraviolet spectrum , Appl. Phys. Lett. 67(3) (1995) 335-337.

[10] M. Topic, H. Stiebig, M. Krause, H. Wagner, Adjustable ultraviolet-sensitive detectors based on amorphous silicon, Appl. Phys. Lett. 78(16) (2001) 2387-2389.

[11] G. deCesare, F. Irrera, F. Lemmi, F. Palme, Tunable photodetectors based on amorphous Si/SiC heterostructures, IEEE Trans. on Electron. Devices 42(5) (1995) 835-840. 
[12] K.-H. Wu, Y.-K- Fang, J.-Y. Fang, J.-D. Hwang, The Growth and Characterization of Silicon/Silicon Carbide Heteroepitaxial Films on Silicon Substrates by Rapid Thermal Chemical Vapor Deposition, Jpn. J. Appl. Phys. 35(1,7) (1996) 3836-3840.

[13] S. Y. Myong, S. S. Kim. K. S. Kim, Improvement of pin-type amorphous silicon solar cell performance by employing double silicon-carbide p -layer structure, J. Appl. Phys. 95(3) (2004) $1525-1530$.

[14] S. Y. Myong, K. S. Kim, J. M. Pears, Double amorphous silicon-carbide p-layer structures producing highly stabilized pin-type protocrystalline silicon multilayer solar cells, Appl. Phys. Lett. 87(19) (2005) 193509,193509-3.

[15] Hargis, P. J. and Greenberg, K. E. and Miller, P. A. and Gerardo, J. B. and Torczynski, J. R. and Riley, M. E. and Hebner, G. A. and Roberts, J. R. and Olthoff, J. K. and Whetstone, J. R. and Van Brunt, R. J. and Sobolewski, M. A. and Anderson, H. M. and Splichal, M. P. and Mock, J. L. and Bletzinger, P. and Garscadden, A. and Gottscho, R. A. and Selwyn, G. and Dalvie, M. and Heidenreich, J. E. and Butterbaugh, Jeffery W. and Brake, M. L. and Passow, M. L. and Pender, J. and Lujan, A. and Elta, M. E. and Graves, D. B. and Sawin, H. H. and Kushner, M. J. and Verdeyen, J. T. and Horwath, R. and Turner, T. R., The Gaseous Electronics Conference radiofrequency reference cell: A defined parallel-plate radio-frequency system for experimental and theoretical studies of plasma-processing discharges, Rev. of Sci. Instrum. 65 (1994) 140-154.

[16] Poukhovoi, S. Schipporeit, H.-W. Becker, L. Calliari, V. Buck, Assessment of spectroscopic methods for the characterisation of DLC films deposited by PECVD, J. Optoel. Adv. Mater. 14 (2012) 383-392.

[17] A. Strecker, U. Salzberger, J. Mayer, "Specimen Preparation for Transmission Electron Microscopy: Reliable Method for Cross Sections and Brittle Materials," Prakt. Metallogr. 30 (1993) 482-495.

[18] A. Steckl, S. Madapura, M. Loboda, Heteroepitaxial Growth of $\mathrm{SiC}$ on $\mathrm{Si}(100)$ and (111) by Chemical Vapor Deposition Using Trimethylsilane, J. Electrochem. Soc. 146(3) (1999) 11971202.

[19] J. Boo, S. Lee, K. Yu, M. Sung, Y. Kim, High vacuum chemical vapor deposition of cubic SiC thin films on $\mathrm{Si}(001)$ substrates using single source precursor, Surf. Coat. Tech. 131(1-3) (2000) 147-152.

[20] M. Mehregany, C. A. Zorman, SiC MEMS: opportunities and challenges for applications in harsh environments, Thin Solid Films 355-356 (1999) 518-524.

[21] D. N. Talwar, J. C. Sherbondy, Thermal expansion coefficient of 3C-SiC , Appl. Phys. Lett. 67 (1995) 3301-3303.

[22] N. Woehrl, Influence of hydrogen on the residual stress in nanocrystalline diamond films, Diamond and Relat. Mater. 16(4-7) (2007) 748-752. 
[23] M.J. Pelletier, Analytical applications of Raman spectroscopy, Blackwell Publishing, Oxford UK (1999).

[24] S. Nakashima and H. Harima, Raman Investigation of SiC Polytypes, phys. stat. sol. 162(1) (1997) 39-64.

[25] H. Hobert, H.H. Dunken, J. Meinschien, H. Stafast, Infrared and Raman spectroscopic investigation of thin films of AlN and SiC on Si substrates, Vib. Spectrosc. 19(2) (1998) 205211.

[26] J. Robertson, Diamond-like amorphous carbon , mater. sci. and eng. R: Rep. 37(4) (2002) 129281.

[27] Y-N. Xu, W.Y. Ching, Electronic, optical, and structural properties of some wurtzite crystals, Phys. Rev. B 48 (1993) 4335-4358.

[28] M. E. Straumanis, P. Borgeaud, W. J. James, Perfection of the Lattice of Dislocation-Free Silicon, Studied by the Lattice-Constant and Density Method, J. Appl. Phys. 32 (1961) 1382-1384.

[29] J. Niemann, W. Bauhofer, Properties of a-Si ${ }_{1-x} C_{x}: H$ thin films deposited from the organosilane Triethylsilane Thin solid films 352 (1999) 249-258.

[30] A.M. Wrobel, I. Blaszczyk-Lezak, A. Walkiewicz-Pietrzykowska, Silicon carbonitride thin-film coatings fabricated by remote hydrogen-nitrogen microwave plasma chemical vapor deposition from a single-source precursor: Growth process, structure, and properties of the coatings, J. Appl. Polym. Sci. 105(1) (2007) 122-129.

\section{FIGURE CAPTION}

FIG. 1. Cross section views of SiC films grown by thermal CVD with different deposition times $(2,5$, 10 and 30 minutes) on Si substrates.

FIG. 2. SiC film thickness as a function of deposition time in thermal CVD process.

FIG. 3. Raman measurements of $\mathrm{SiC}$ films on Si substrate deposited by thermal CVD. Samples differ in

SiC film thickness: (a) $200 \mathrm{~nm}$, (b) $2 \mu \mathrm{m}$, (c) $9 \mu \mathrm{m}$ 
FIG. 4. SEM pictures of Si films grown by thermal CVD at different deposition times (1 minute and 10 minutes) by Ar diluted $\mathrm{SiH}_{4}(1: 80)$.

FIG. 5. XRD of Si films deposited by thermal CVD at $1000{ }^{\circ} \mathrm{C}$ for one minute.

FIG. 6. Overview of the cross section of a four-layer-film on a SiC substrate as a composition of TEM images (a) and close up (b). HRTEM of the interface of the first Si layer and the SiC substrate (c) with FTs of the substrate (I) and of the boxed area of the Si layer (II) as insets (additional Bragg peaks at position of half way of $\{131\}$ arise from an adjacent crystal).

FIG. 7. HRTEM image of the interface of the second SiC layer and the third Si layer (a). STEM bright field of the four-layer-film in cross section with profile of the C-K net counts from EDS-linescan as overlay (b).

FIG. 8. SEM picture of a cross section view of the ten-layer system deposited by thermal CVD.

FIG. 9. SiC film thickness (measured by profilometry) as a function of deposition time deposited by PECVD. 
FIG. 10. SiC film thickness (measured by ellipsometry) as a function of $\mathrm{Et}_{3} \mathrm{SiH}$-flow deposited by PECVD.

FIG. 11. SiC film thickness (measured by profilometry) as a function of substrate temperature deposited by PECVD.

FIG. 12. AFM line scan with surface roughness measurement for a SiC film deposited by PECVD.

FIG. 13. Grazing incidence XRD measurements at $1^{\circ}$ of samples deposited by PECVD

FIG. 14. SIMS measurement of a SiC film on silicon substrate as deposited by PECVD. 


\section{DuEPublico}

Duisburg-Essen Publications online

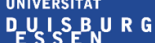

offen im Denken

\section{$\mathbf{u b} \mid \begin{gathered}\text { universitäts } \\ \text { bibliothek }\end{gathered}$}

This text is made available via DuEPublico, the institutional repository of the University of Duisburg-Essen. This version may eventually differ from another version distributed by a commercial publisher.

DOI: $\quad$ 10.1016/j.tsf.2015.08.042

URN: urn:nbn:de:hbz:464-20201125-133631-1

This is the Authors Accepted Manuscript of an article published in: Thin Solid Films 593 (2015) 44-52. The final version may be found at: https://doi.org/10.1016/j.tsf.2015.08.042 